\title{
Anthracene appended pyridinium amide-urea conjugate in selective fluorometric sensing of L-N-acetylvaline salt
}

\author{
Kumaresh Ghosh", Tanmay Sarkar and Asoke P. Chattopadhyay
}

\section{Letter}

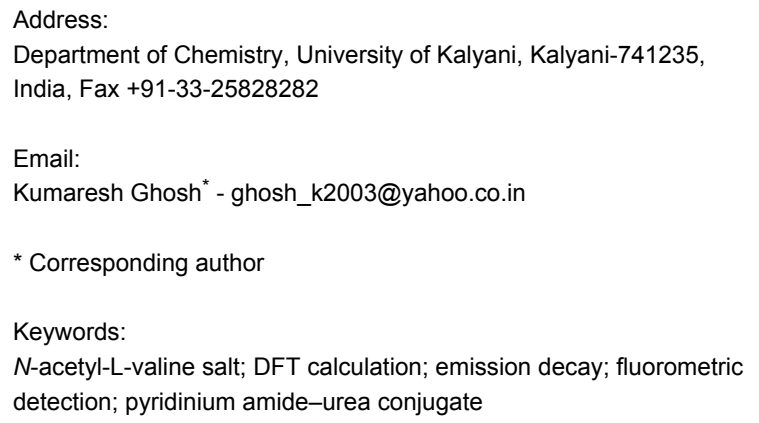

\author{
Beilstein J. Org. Chem. 2010, 6, 1211-1218. \\ doi:10.3762/bjoc.6.139 \\ Received: 02 August 2010 \\ Accepted: 16 November 2010 \\ Published: 21 December 2010 \\ Associate Editor: S. C. Zimmerman \\ (C) 2010 Ghosh et al; licensee Beilstein-Institut. \\ License and terms: see end of document.
}

\begin{abstract}
A new anthracene labeled pyridinium amide-urea conjugate $\mathbf{1}$ has been designed and synthesized. The receptor shows a different fluorometric response with L- $N$-acetylvaline and L-N-acetylalanine salts in $\mathrm{CH}_{3} \mathrm{CN}$ in contrast to the other salts of $\mathrm{L}-\mathrm{N}$-acetyl $\alpha$-amino acids and $(S)$ - $\alpha$-hydroxy acids studied. Upon complexation of the tetrabutylammonium salt of L- $N$-acetylvaline, the emission of 1 increases accompanied by the formation of a new band at higher wavelength and this characteristic change distinguishes it from other anionic substrates studied. The binding interaction has been studied by ${ }^{1} \mathrm{H}$ NMR, fluorescence and UV titration experiments.
\end{abstract}

\section{Introduction}

The design and synthesis of artificial receptors capable of recognizing $\alpha$-hydroxy and $N$-acetyl- $\alpha$-amino acid carboxylates (i.e., salts of $\alpha$-amino acids) is an active area of interest in supramolecular chemistry due to the biological significance and practical importance of $\alpha$-amino and $\alpha$-hydroxy acids [1-7]. While $\alpha$-hydroxycarboxylic acids are useful synthons for many organic natural products and drug molecules, $\alpha$-amino carboxylic acids are important as they are the building blocks of proteins, enzymes etc., which govern numerous biochemical processes. In this context, detection and sensing of these molecules by fluorescence spectroscopy offers a variety of advantages such as different detection modes (fluorescence quenching, enhancement and life time), high sensitivity, low instrumentation cost, time efficiency, and the possibility of performing real time analysis. However, the development of receptors for these molecules is slow due to their insolubility in organic solvents, especially amino acids. For strong complexation of zwitterionic amino acids, synthetic receptors should possess complementary binding sites for both ammonium and carboxylate functionalities. Examples in this domain are known in the literature [8-15]. To overcome the solubility problem, $\alpha$-amino acids are sometimes converted into their $\mathrm{N}$-acetyl derivatives which makes their recognition easier in organic solvents [16-19], as these are non-competitive solvents and 
$\mathrm{O}_{2} \mathrm{~N}$<smiles>Cc1ccc(NC(=O)Nc2cccc(C(=O)Nc3c(C)cc[n+](Cc4c(C)ccc5ccccc45)c3C)c2)cc1</smiles><smiles>CCCC(=O)Nc1cccc(C(=O)NC)c1</smiles>

2<smiles>Nc1ccc[n+](Cc2c3ccccc3cc3ccccc23)c1</smiles>

Figure 1: Synthesized compounds 1 and 2.

guests exhibit minimal solubility. Hamilton et al. introduced simple pyridine amide-based receptors for the effective recognition of $N$-acetyl- $\alpha$-amino acids by multiple hydrogen bonding interactions [20]. During our work on selective recognition of different anionic species including carboxylates [21,22], we reported receptors of various structures with different binding sites. The pyridinium motif, which was first used by Jeong et al. for carboxylate binding [23], was one of the binding sites in our designed receptors [24-26]. The pyridinium motif is unique due to its contribution to the charge-charge interaction and formation of unconventional hydrogen bonds with the anionic guests [27]. In order to explore this binding site for a wide range of substrates, especially for amino acid derivatives, we report here the design and synthesis of a new fluororeceptor $\mathbf{1}$ where anthracene is attached to the binding site through a covalent $\mathrm{CH}_{2}$ spacer to yield a photo induced electron transfer sensory system [28]. The receptor 1 shows effective binding of the tetrabutylammonium salt of L- $N$-acetylvaline by exhibiting significant change in emission.

Complexation induced formation of an exciplex or charge transfer complex in $\mathrm{CH}_{3} \mathrm{CN}$ is the key feature in the present study for the selective detection of a $\mathrm{L}-\mathrm{N}$-acetylvaline salt from other anionic guests. To explain the formation of an exciplex or charge transfer complex in $\mathbf{1}$ upon complexation of L- $N$-acetylvaline salt, compound $\mathbf{2}$ was synthesized and studied (see Figure 1).

\section{Results and Discussion}

Compounds $\mathbf{1}$ and $\mathbf{2}$ were synthesized according to Scheme 1. Initially, 3-nitrobenzoyl chloride was reacted with 3-aminopyridine to give the amide 3. Reduction of the $-\mathrm{NO}_{2}$ group in $\mathbf{3}$ with $\mathrm{SnCl}_{2}$ in EtOAc afforded the amine 4, which was further a) $52 \%$

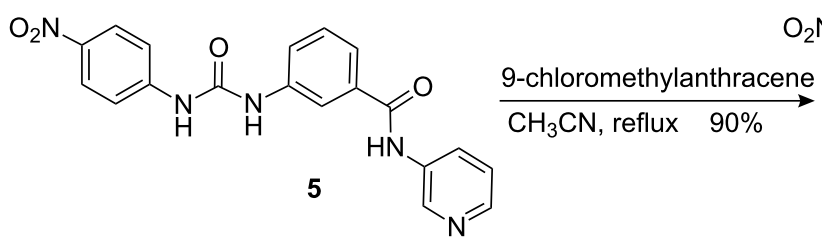

b)<smiles>Nc1cccc(C(=O)Nc2cccnc2)c1</smiles>
$n$-butyryl chloride, $\mathrm{Et}_{3} \mathrm{~N}$<smiles>N=Cc1cccc([N+](=O)[O-])c1</smiles>

3<smiles>Nc1cccnc1</smiles><smiles>CCCC(=O)Nc1cccc(C(=O)Nc2cccnc2)c1</smiles><smiles>CCOC(=O)COc1ccccc1</smiles><smiles>CCCCC</smiles>
$\underset{\text { 4-nitroaniline } \quad 60 \%}{\stackrel{2}{\longrightarrow}}$

$\mathrm{HN}$<smiles>c1ccncc1</smiles>

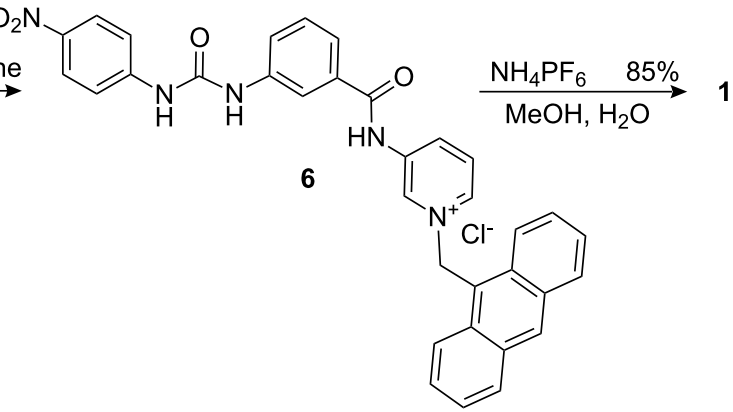

i) 9-chloromethylanthracene $\mathrm{CH}_{3} \mathrm{CN}$, reflux $\quad 76 \%$

ii) $\mathrm{NH}_{4} \mathrm{PF}_{6}, \mathrm{MeOH}, \mathrm{H}_{2} \mathrm{O} \quad 90 \%$ 
reacted with 4-nitrophenyl isocyanate (obtained from 4-nitroaniline by reaction with triphosgene in dry THF) in dry THF to give urea derivative $\mathbf{5}$. Subsequent reaction of $\mathbf{5}$ with 9-chloromethylanthracene under refluxing conditions in dry $\mathrm{CH}_{3} \mathrm{CN}$ gave the chloride salt $\mathbf{6}$. Anion exchange of the salt 6 with $\mathrm{NH}_{4} \mathrm{PF}_{6}$ afforded the desired receptor 1 as a white solid. Compound $\mathbf{2}$ was obtained from the intermediate amine $\mathbf{4}$ after performing a series of reactions such as amide formation, alkylation on pyridine ring nitrogen followed by anion exchange with $\mathrm{NH}_{4} \mathrm{PF}_{6}$ (Scheme $1 \mathrm{~b}$ ). Compounds 1 and $\mathbf{2}$ were characterized by ${ }^{1} \mathrm{H}$ NMR, ${ }^{13} \mathrm{C}$ NMR, FTIR and mass spectrometry.

The solution phase binding interaction of the tetrabutylammonium salts of L- $N$-acetylalanine, L- $N$-acetylvaline, L- $N$-acetylproline and L- $N$-acetylphenylglycine, $(S)$-mandelic and pyruvic acids was investigated by ${ }^{1} \mathrm{H}$ NMR, UV-vis and fluorescence techniques. Initially, we recorded the ${ }^{1} \mathrm{H}$ NMR of $\mathbf{1}$ in the presence and the absence of the guests in $\mathrm{CDCl}_{3}$ containing $0.4 \%$ $d_{6}$-DMSO (due to insolubility of $\mathbf{1}$ in pure $\mathrm{CDCl}_{3}$ ). In the presence of equivalent amounts of all the guests, urea $\left(\Delta \delta_{\mathrm{NHb}}=\right.$ $\left.0.93-1.90, \Delta \delta_{\mathrm{NHc}}=0.87-1.96\right)$ and amide protons $\left(\Delta \delta_{\mathrm{NHa}}=\right.$ $0.46-0.79)$ underwent downfield shifts suggesting their involvement in the binding process. In addition, the pyridinium ortho proton $\left(\mathrm{H}_{\mathrm{o}}\right)$ in 1 was also downfield shifted $(\Delta \delta=0.83-1.06)$ which indicated its involvement in the formation of strong hydrogen bonding with the carboxylate moiety of the guests. In contrast, the pyridinium para proton $\left(\mathrm{H}_{\mathrm{p}}\right)$ showed a small downfield shift $(\Delta \delta=0.02-0.48)$. This small change in chemical shift of the para proton is due to either a change in bond length of the intramolecular hydrogen bond between the amide carbonyl oxygen and para hydrogen of pyridinium motif, or involvement in the formation of a hydrogen bond with the guest in solution. On addition of an equivalent amount of tetrabutylammonium salts of acetate and pyruvate to the solution of $\mathbf{1}$, precipitation occurred. A similar finding was observed in the presence of an equivalent amount of the alanine salt. Figure 2 shows the change in ${ }^{1} \mathrm{H}$ NMR spectrum of 1 in presence of an equivalent amount of tetrabutylammonium salts of L- $N$-acetylvaline, L- $N$-acetylproline and $(S)$-mandelic acid.

Once it was realized that both urea and pyridinium sites of $\mathbf{1}$ are involved in hydrogen bonding with the guests studied, we recorded the emission spectra of $\mathbf{1}$ in $\mathrm{CH}_{3} \mathrm{CN}$. Receptor $\mathbf{1}$ showed an intense emission at $415 \mathrm{~nm}$ when excited at $370 \mathrm{~nm}$ in $\mathrm{CH}_{3} \mathrm{CN}$. Upon gradual addition of the guests to a solution of $1\left(c=4.31 \times 10^{-5} \mathrm{M}\right)$ in $\mathrm{CH}_{3} \mathrm{CN}$, the emission at $415 \mathrm{~nm}$ was changed differently. For all guests, except the salts of L- $N$ acetylvaline and L- $N$-acetylalanine, emission of 1 at $415 \mathrm{~nm}$ decreased gradually (Supporting Information File 1). However, in the case of the L- $N$-acetylvaline salt, a broad emission at $492 \mathrm{~nm}$ with moderate intensity was observed. Figure 3 displays

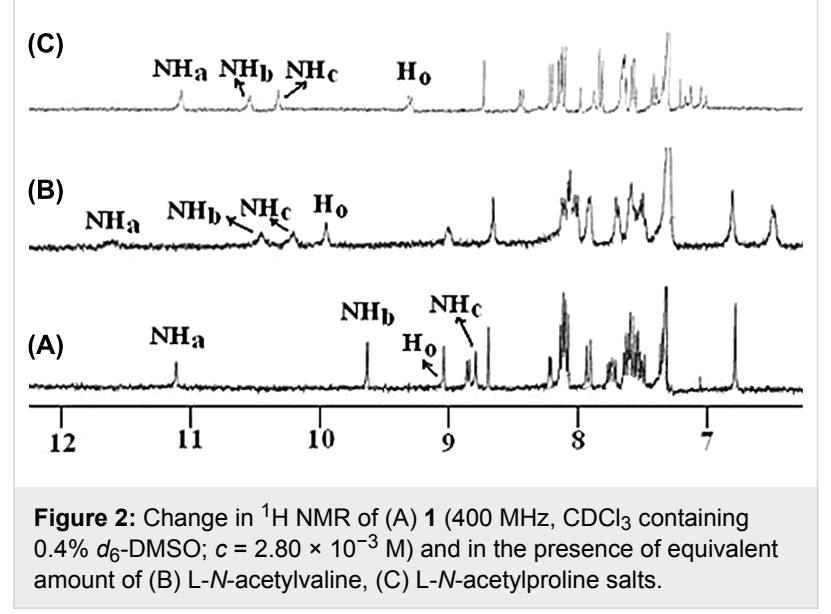

the change in emission of $\mathbf{1}$ at $492 \mathrm{~nm}$ in the presence of one equivalent of each guest in $\mathrm{CH}_{3} \mathrm{CN}$. The increase in emission of 1 at $492 \mathrm{~nm}$ in the presence of tetrabutylammonium salts of $\mathrm{L}-\mathrm{N}$-acetylvaline and L- $N$-acetylalanine is moderate and distinguishable from the other guests. It is worth noting that the appearance of the new emission at $492 \mathrm{~nm}$ is more significant in the presence of L- $N$-acetylvaline salt than with L- $N$-acetylalanine. This is attributed to the formation of a charge transfer complex between the excited state of anthracene and the electron deficient nitrophenyl urea during the interaction process. We believe that this characteristic feature with L- $N$-acetylvaline is due to its structural feature that controls the distance between donor and acceptor.

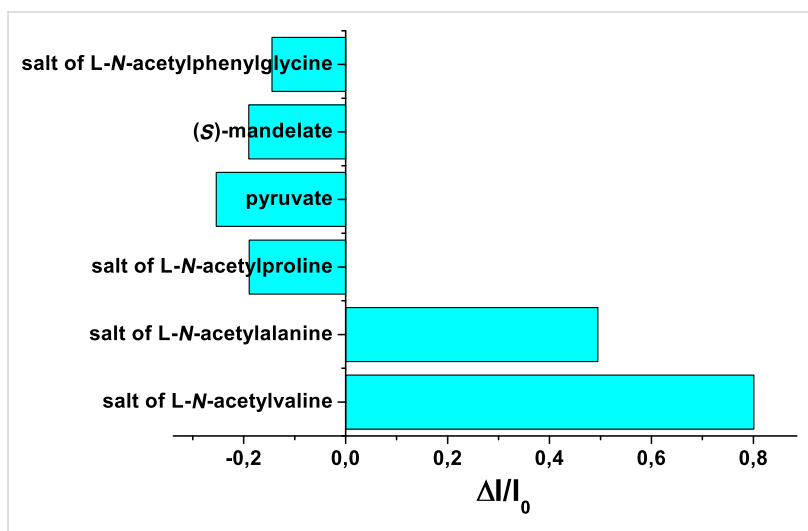

Figure 3: Change in fluorescence ratio of 1 upon addition of one equivalent of anions $\left(c=4.31 \times 10^{-5} \mathrm{M}\right)$ at $492 \mathrm{~nm}$.

Figure $4 \mathrm{a}$ and Figure $4 \mathrm{~b}$ show the change in emission of 1 ( $c=$ $\left.4.31 \times 10^{-5} \mathrm{M}\right)$ upon increasing the quantity of tetrabutylammonium salts of L- $N$-acetylvaline and L- $N$-acetylalanine, respectively. The expected charge transfer in $\mathbf{1}$ upon complexation of valine salt was further established by performing similar fluorescence titration experiment with the receptor $\mathbf{2}$, where the electron deficient urea motif is absent. In this case, no broad 

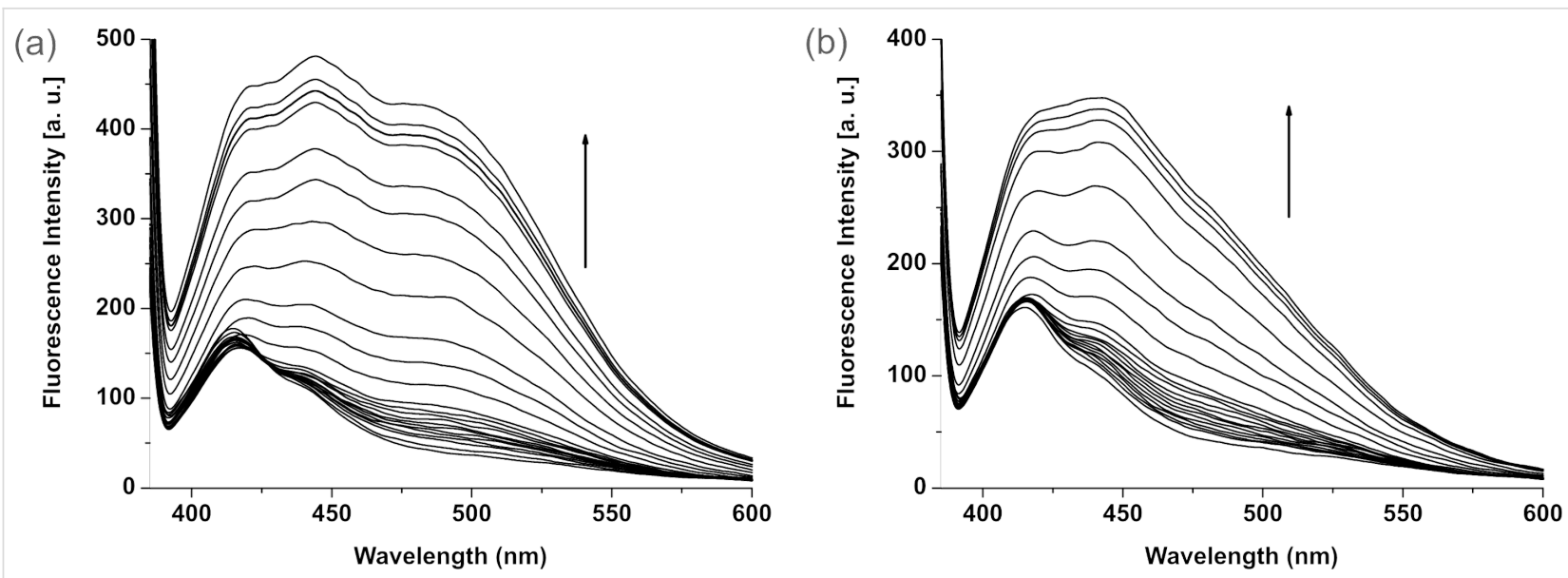

Figure 4: Change in emission of $1\left(c=4.31 \times 10^{-5} \mathrm{M}\right)$ upon gradual addition of tetrabutylammonium salts of (a) L-N-acetylvaline and (b) L-N-acetylalanine.

band at $492 \mathrm{~nm}$ was observed when the titration was carried out by gradual addition of the valine salt (Supporting Information File 1). This was also the case for the alanine salt. The other salts merely perturbed the emission of $\mathbf{2}$ and thus indicate the positive role of the urea motif in $\mathbf{1}$ for effective complexation of anionic substrates. This is in accordance with Hamilton's observation [20].

The different modes of emission (enhancing and quenching) of 1 in the presence of the different guests studied is believed to be due to the structural difference and hydrogen bonding abilities of the guests for which the PET process occurring between the amide-urea binding site and the excited state of anthracene is regulated in different ways. We presume that receptor $\mathbf{1}$ may follow any equilibrium-binding mode $\mathbf{A}, \mathbf{B}$ or $\mathbf{C}$ with valine, alanine and phenylglycine salts in solution as shown in Figure 5. This is also true for the mandelate, pyruvate and proline salts. Relevance of the suggested modes in Figure 5 was followed from the change in chemical shift of the key protons of $\mathbf{1}$ in the ${ }^{1} \mathrm{H}$ NMR upon complexation (see Figure 2) as well as from Hamilton's observation on related systems [3]. In the interaction process, the stoichiometry of the complexes was 1:1 as confirmed by Job plots (Supporting Information File 1). In addition, the break in the titration curves at $[\mathrm{G}] /[\mathrm{H}]=1$ in Figure 6 also supports this stoichiometry. A closer look at the curves for L- $N$-acetylvaline and L-N-acetylalanine salts in

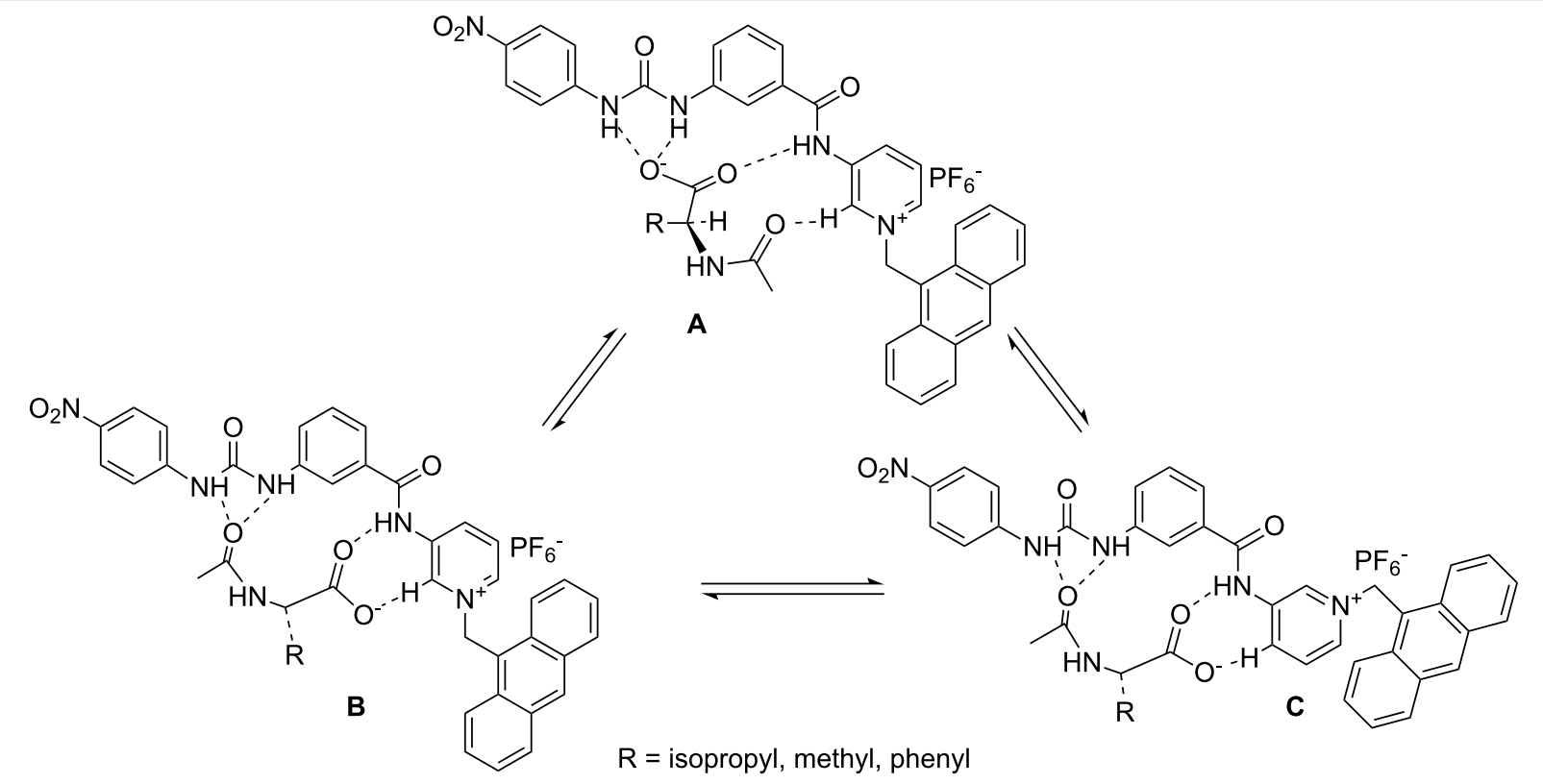

Figure 5: Suggested modes of binding of the amino acid salts into the open cleft of 1. 
Figure 6 shows that there are breaks at $[\mathrm{G}] /[\mathrm{H}]=1$ within the range of 3 equivalents of the added guest. Further addition causes a steady increase in emission and reaches saturation only when 20 to 30 equivalent amounts of the guest are added (Supporting Information File 1). This result suggests that in the presence of a large excess of the L- $N$-acetylvaline and L- $N$ acetylalanine salts that complexes with higher order stoichiometries are being formed in solution. The almost linear nature of the titration curves for all other guests except L- $N$-acetylvaline and L- $N$-acetylalanine salts at $492 \mathrm{~nm}$ (Figure 6) corroborated the weak interaction.

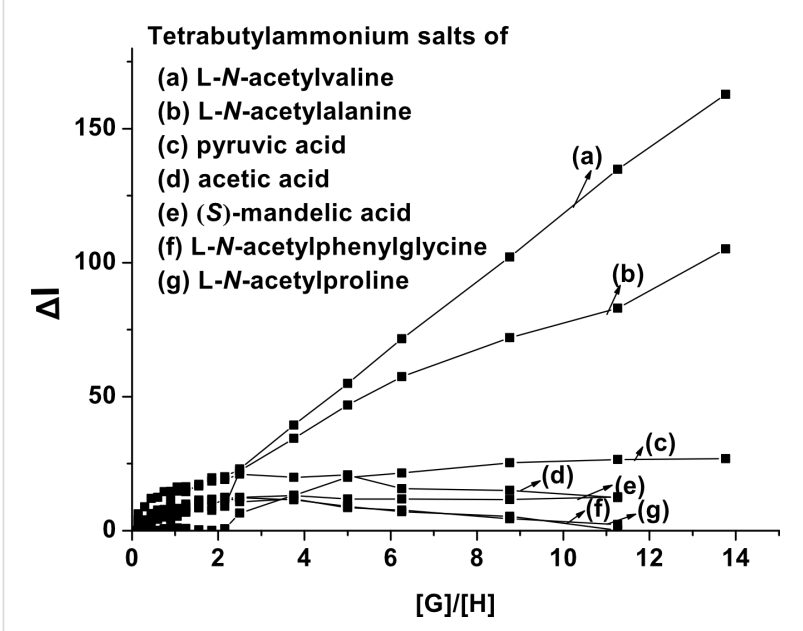

Figure 6: Fluorescence titration curves for $1\left(c=4.31 \times 10^{-5} \mathrm{M}\right)$ at $492 \mathrm{~nm}$.

The time resolved emissions for $\mathbf{1}$ and $\mathbf{2}$ upon excitation at $370 \mathrm{~nm}$ were then studied to have an insight into the interaction process. The emission decay profile of 1 monitored at $420 \mathrm{~nm}$ could be fitted bi-exponential with two constants $\tau_{1}=0.46 \mathrm{ps}$ $(100 \%), \tau_{2}=2.59 \mathrm{~ns}(0 \%)$. The faster decay component $(0.46$ ps) is either due to a very short-lived species or an artifact, or for tunneling of extra energy to the bulk by a non-radiative pathway $[29,30]$. The emitting species with a life time of
$2.59 \mathrm{~ns}$ is real. However, in the presence of 1 equiv of L-Nacetylvaline salt, the decay profile followed a tri-exponential fitting that indicated three emitting species with life times $\tau_{1}=$ $1 \mathrm{~ns}(0.02 \%), \tau_{2}=4.23 \mathrm{~ns}(0.02 \%)$ and $\tau_{3}=0.62 \mathrm{ps}(99.96 \%)$ (Figure 7). Among these, the fast decay component $0.62 \mathrm{ps}$ could be attributed to the formation of a hydrogen-bonded short-lived species where presumably intramolecular charge transfer between anthracene and nitrophenyl urea as represented in Figure 4a, takes place. This component coexists with the other components contributing large preexponential factor to the total fluorescence. This finding was not observed with L- $N$-acetylalanine or L- $N$-acetylproline salts (Table 1). Neither was this observed when the emission decay of 2 was monitored at $418 \mathrm{~nm}$ in the presence of L- $N$-acetylvaline salt upon excitation at $370 \mathrm{~nm}$. This observation is thus noteworthy since it distinguishes the L- $N$-acetylvaline salt in the present study form the others with receptor 1 .

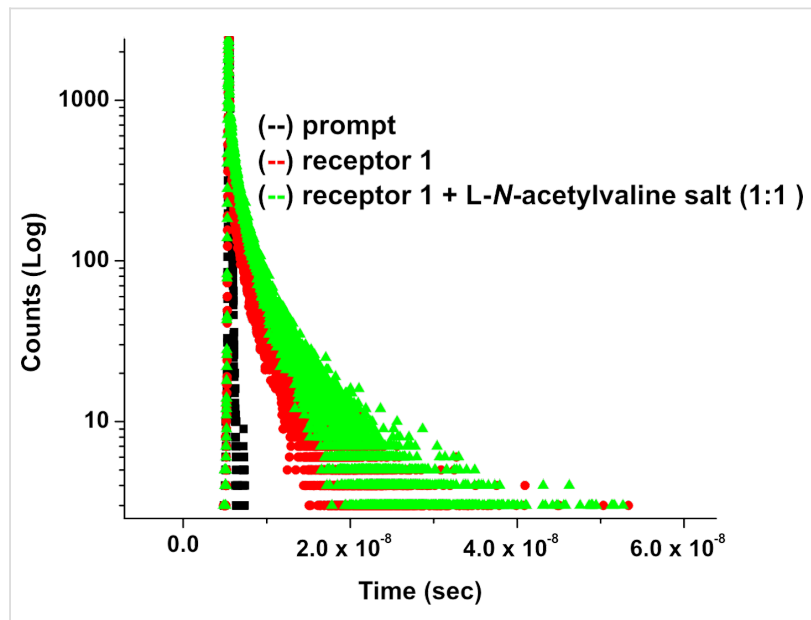

Figure 7: Fluorescence decays (at $\lambda_{\max }=420 \mathrm{~nm}$ ) of receptor 1 upon the addition of 1 equiv of $\mathrm{L}-\mathrm{N}$-acetylvaline salt $\left([\mathrm{H}]=4.71 \times 10^{-5} \mathrm{M}\right.$, [G] $\left.=9.42 \times 10^{-4} \mathrm{M}\right)$ in $\mathrm{CH}_{3} \mathrm{CN}$.

Concurrently, the ground state binding properties of $\mathbf{1}$ in $\mathrm{CH}_{3} \mathrm{CN}$ were evaluated by $\mathrm{UV}$-vis studies. The absorption

Table 1: Fluorescence decay times ( $\mathrm{T}$ ), and preexponential factors for $\mathbf{1}$ and $\mathbf{2}$ in $\mathrm{CH}_{3} \mathrm{CN}$.

Receptor in presence and absence of guest

$\mathbf{1}$
$\mathbf{1}+1$ equiv $L-N$-acetylvaline salt
$\mathbf{1}+1$ equiv $L-N$-acetylalanine salt
$\mathbf{1}+1$ equiv $L-N$-acetylproline salt
$\mathbf{2}$
$\mathbf{2}+1$ equiv $L-N$-acetylvaline salt
$\mathbf{2}+1$ equiv $L-N$-acetylalanine salt
$\mathbf{2}+1$ equiv $L-N$-acetylproline salt

Fluorescence decay time т (preexponential factor)

$$
\begin{aligned}
& \mathrm{T}_{1}=0.46 \mathrm{ps}(100 \%), \mathrm{T}_{2}=2.59 \mathrm{~ns}(0 \%) ;\left(\mathrm{X}^{2}=1.43\right) \\
& \mathrm{T}_{1}=1 \mathrm{~ns}(0.02 \%), \mathrm{T}_{2}=4.23 \mathrm{~ns}(0.02 \%), \mathrm{T}_{3}=0.62 \mathrm{ps}(99.96 \%) ;\left(\mathrm{X}^{2}=1.08\right) \\
& \mathrm{T}_{1}=5.0 \mathrm{ps}(58.83 \%), \mathrm{T}_{2}=2.75 \mathrm{~ns}(41.17 \%) ;\left(\mathrm{X}^{2}=1.03\right) \\
& \mathrm{T}_{1}=2.5 \mathrm{ps}(85.56 \%), \mathrm{T}_{2}=2.76 \mathrm{~ns}(14.44 \%) ;\left(\mathrm{X}^{2}=1.15\right) \\
& \mathrm{T}_{1}=0.58 \mathrm{ps}(99.98 \%), \mathrm{T}_{2}=3.92 \mathrm{~ns}(0.02 \%) ;\left(\mathrm{X}^{2}=1.54\right) \\
& \mathrm{T}_{1}=0.63 \mathrm{ps}(99.95 \%), \mathrm{T}_{2}=3.87 \mathrm{~ns}(0.05 \%) ;\left(\mathrm{X}^{2}=1.72\right) \\
& \mathrm{T}_{1}=2.52 \mathrm{ps}(65.38 \%), \mathrm{T}_{2}=3.84 \mathrm{~ns}(34.62 \%) ;\left(\mathrm{X}^{2}=1.69\right) \\
& \mathrm{T}_{1}=0.49 \mathrm{ps}(100 \%), \mathrm{T}_{2}=4.18 \mathrm{~ns}(0 \%) ;\left(\mathrm{X}^{2}=1.36\right)
\end{aligned}
$$


spectrum of $1\left(c=4.31 \times 10^{-5} \mathrm{M}\right)$ in the absence of anions showed a structured band with maximum intensity at $341 \mathrm{~nm}$. Upon titration with the salt of L- $N$-acetylvaline the ground state of 1 was affected significantly and the absorption was weakly red shifted because of recognition of the anion and a distinctive isosbestic point was observed at $340 \mathrm{~nm}$ (Figure 8). Similar observations were noted with the other guests (Supporting Information File 1). The stoichiometry of the interaction process in the ground state was also 1:1 as established from the break in the titration curves as well as Job plots [31] (Supporting Information File 1). In the titration curves, downward running of the titration curves in few cases indicates that as a greater excess of the guest anion is added, the 1:1 host-guest complex is assumed to be disrupted and anions begin to bind individually to the pyridinium amide and urea binding sites, rather than in a cooperative manner. Thus, in principle, equilibrium complexes of multiple stoichiometries can be generated in solution. This behavior depends on the anions [32] and also on the concentrations of the host and guest used at which the titration experiments are monitored.

Analysis of the emission data provided the association constants $\left(K_{\mathrm{a}}\right)$, reported in Table 2 [33]. For determining binding constant values for $\mathrm{L}-\mathrm{N}$-acetylvaline and $\mathrm{L}-\mathrm{N}$-acetylalanine salts, we considered the emission data up to the addition of 13 equivalents of the guests added, since in the presence of large excess of such guests complex stoichiometries were noted. From Table 2 it can be seen that receptor 1 exhibits higher binding constant values for L- $N$-acetylvaline in the series. At this moment, we believe that it is due to structural aspects as well as to the hydrogen bonding capacity of the valine salt. Furthermore, to establish the hydrogen bonding influence of the acylamino and hydroxy groups of the amino and hydroxy acids respectively, we determined the binding constant for the acetate anion. This was found to be slightly less when compared to all the other guests. Pyruvate with carbonyl at the $\alpha$-position did not produce any marked change in emission of $\mathbf{1}$. We also determined the binding constants for 2 with the same anions in

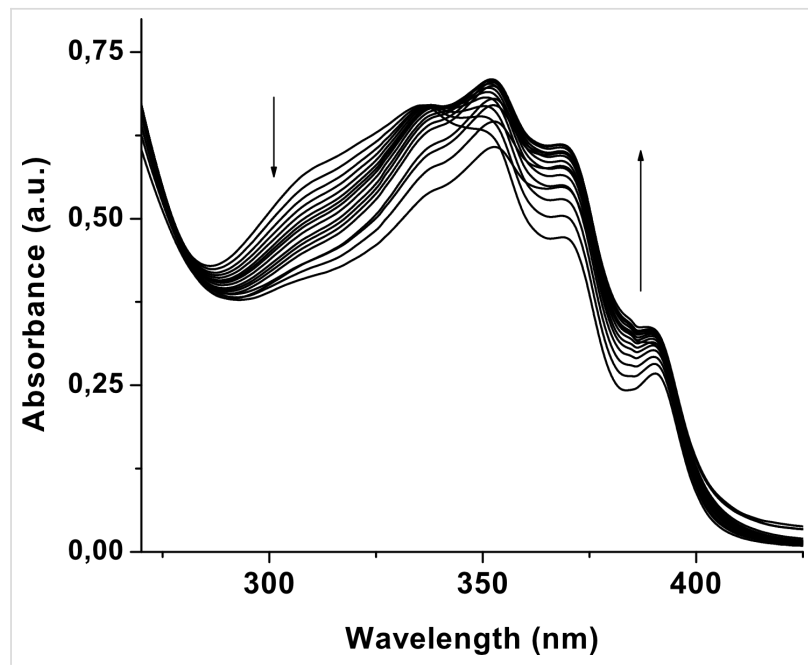

Figure 8: Change in absorbance of $1\left(c=4.31 \times 10^{-5} \mathrm{M}\right)$ upon gradual addition of tetrabutylammonium salts of $\mathrm{L}-\mathrm{N}$-acetylvaline.

$\mathrm{CH}_{3} \mathrm{CN}$ by fluorescence (Table 2) and the values were found to be less compared to the values for $\mathbf{1}$. This is in accordance with Hamilton's observation [3] and indicates the role of the urea motif in the binding event.

In order to realize the conformational behavior and the reactivity of $\mathbf{1}$ towards hydrogen bonding with the anionic guests as noted in Table 2, we carried out detailed DFT calculations. The Gaussian-03 package [34] and GAMESS-US suite [35] (version April 11, 2008) was used for the calculations and the MO figures were obtained using the MaSK software [36]. DFT calculations were performed in the gas phase on the two different conformations of 1 using the $6-311 \mathrm{G}^{* *}$ basis set [37] and the popular b3LYP functional $[38,39]$. Similar calculations were also carried out on all the guests given in Table 2. For all the compounds, parameters such as global electrophilicity $(\omega)$, global electronegativity $(\chi)$, global hardness $(\eta)$, dipole moment $(\mu)$ and the energies of HOMO and LUMO are also reported (Table S1; Supporting Information File 1) from their DFT optimized structures [34-36]. The orientation of the binding sites in

\begin{tabular}{|c|c|c|}
\hline Guest $^{a}$ & $\begin{array}{l}\text { Receptor } 1 \\
K_{\mathrm{a}}\left[\mathrm{M}^{-1}\right]^{\mathrm{e}}\end{array}$ & $\begin{array}{l}\text { Receptor } \mathbf{2} \\
K_{\mathrm{a}}\left[\mathrm{M}^{-1}\right]^{\mathrm{e}}\end{array}$ \\
\hline L-N-acetylvaline & $1.87 \times 10^{4} ; R=0.998^{c}$ & $1.30 \times 10^{3} ; R=0.988^{c}$ \\
\hline L-N-acetylalanine & $2.60 \times 10^{3} ; R=0.995^{d}$ & $6.50 \times 10^{2} ; \mathrm{R}=0.993^{\mathrm{C}}$ \\
\hline L-N-acetylproline & $1.38 \times 10^{3} ; R=0.993^{c}$ & $-^{b}$ \\
\hline L-N-acetylphenylglycine & $1.31 \times 10^{3} ; R=0.989^{c}$ & $-^{b}$ \\
\hline acetate & $2.20 \times 10^{3} ; \mathrm{R}=0.997^{c}$ & $1.70 \times 10^{3} ; R=0.998^{c}$ \\
\hline (S)-mandelate & $1.60 \times 10^{3} ; R=0.995^{c}$ & $-^{\mathrm{b}}$ \\
\hline pyruvate & $-^{\mathrm{b}}$ & $-^{\mathrm{b}}$ \\
\hline
\end{tabular}

atetrabutylammonium salts were used; ${ }^{b}$ not determined due to irregular change; ${ }^{c}$ determined at $414 \mathrm{~nm}$; ${ }^{\mathrm{d}}$ determined at $492 \mathrm{~nm}$; ${ }^{\mathrm{e} e r r o r} \leq 10 \%$. 
both 1A and 1B are displayed in Figure S15 (Supporting Information File 1). Of the two possible conformations of receptor $\mathbf{1}$ (Figure S15), 1B is found to be more stable than $\mathbf{1 A}$ by 2.82 $\mathrm{kcal} / \mathrm{mol}$. Therefore, we may reasonably expect that in solution both conformers may remain in equilibrium. However, conformation 1A may form a more stable hydrogen-bonded complex with guests, owing to formation of a greater number of hydrogen bonds with the guests. For example, Figure 9 demonstrates the hydrogen-bonded complex of $\mathbf{1 A}$ with $\mathrm{N}$-acetyl-Lvaline carboxylate, where both the urea and pyridinium motifs are cooperatively involved in bonding.

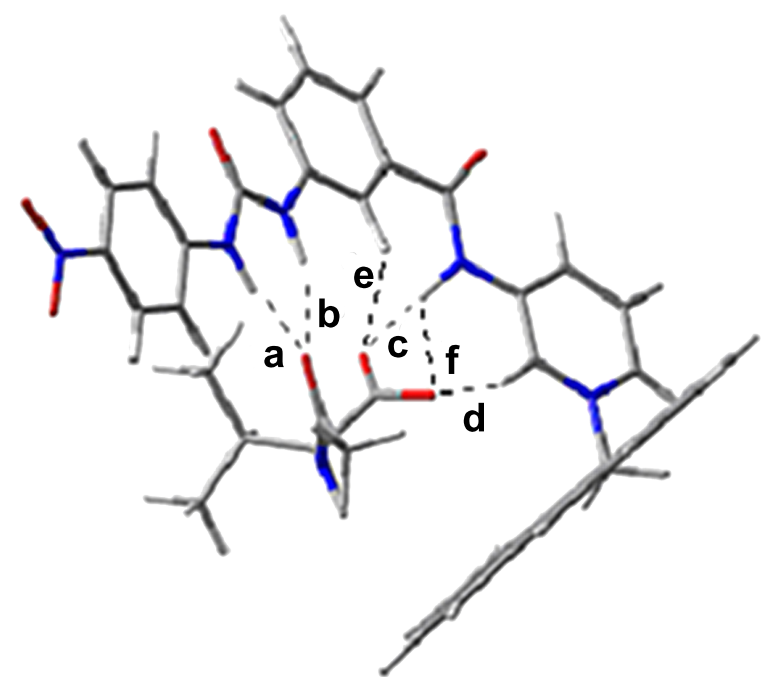

Figure 9: DFT optimized geometry of the complex of 1 with $L-N$-acetylvaline carboxylate salt $[a=1.93 \AA, b=1.99 \AA, c=1.64 \AA, d=1.97 \AA$, $e=2.60 \AA$ and $f=2.69 \AA]$.

However, interaction between the electrophile and the nucleophile can be quantified in terms of the electrophilicity index $(\omega)$ of individual species involved in the process. Although $\omega$ of structure $\mathbf{1 A}$ is found to be only slightly different from that of 1B (Supporting Information File 1), it is obvious that structure 1 has an affinity for anionic guests. As can be seen from Table S1 (Supporting Information File 1), guests such as the salts of valine, phenylglycine and mandelic acid exhibit the lowest values of $\omega$ among all anionic guests considered. This indicates that these guests have higher nucleophilic character compared to the other guests studied. Therefore, receptor $\mathbf{1}$, in principle, will show strong binding for these salts. Experimental results support this observation (see Table 2). Furthermore, to rationalize the preferential mode of interaction of the carboxylate guests with the two different binding domains (urea and pyridinium sites) of receptor 1, we further calculated Fukui functions [40] for nucleophilic attack $\left(f_{\mathrm{k}}^{+}\right)$at these two sites. The larger the value, the greater is the reactivity of the site towards a nucleophile. Between the two sites of $\mathbf{1}$, pyridinium amide exhibits a value of 0.5384 , which is significantly greater than the value obtained for urea site (0.0021) and thus binding of the carboxylate part of all the guests will take place preferentially at the pyridinium site instead of urea (see structures $\mathbf{B} / \mathbf{C}$ in Figure 5).

In conclusion, we have designed and synthesized a new fluororeceptor 1 , which is able to bind $\alpha$-acylamino as well as hydroxy acids with moderate binding constant values. The receptor clearly distinguishes L- $N$-acetylvaline and L- $N$-acetylalanine salts from the other anionic substrates studied by exhibiting different modes of emission. The appearance of charge transfer band and three decay components in time resolved spectroscopy upon complexation of L-N-acetylvaline salt are the distinct features in the present study to distinguish it from the other anions examined. Further progress in this direction is underway in our laboratory.

\section{Supporting Information}

Synthesis and characterization data for $\mathbf{1}$ and $\mathbf{2}$, general procedure for fluorescence and UV titrations, change in absorption and fluorescence spectra, Job plots of receptor 1 with few selected guests, change in emission of $\mathbf{2}$ in the presence of few selected anions, UV titration curves for $\mathbf{1}$, selected binding constant curve for $\mathbf{1}$, change in emission of 1 upon dilution with solvent, titration curves for $\mathbf{1}$ with valine and alanine salts, DFT optimized geometry of $\mathbf{1}$ and MO energies, global hardness, global electronegativity, global electropositivity, dipole moment etc. are available.

\section{Supporting Information File 1}

Detailed experimental data for $\mathbf{1}$ and $\mathbf{2}$.

[http://www.beilstein-journals.org/bjoc/content/ supplementary/1860-5397-6-139-S1.pdf]

\section{Acknowledgements}

We thank CSIR, Government of India for financial support. TS thanks CSIR, New Delhi, India for a fellowship. We also thank DST, Government of India for providing facilities in the department under FIST program.

\section{References}

1. Lin, J.; Hu, Q.-S.; Xu, M.-H.; Pu, L. J. Am. Chem. Soc. 2002, 124 , 2088. doi:10.1021/ja011971x

2. Li, Z.-B.; Lin, J.; Pu, L. Angew. Chem., Int. Ed. 2005, 44, 1690. doi:10.1002/anie.200462471

3. Li, Z.; Lin, J.; Qin, Y.; Pu, L. Org. Lett. 2005, 7, 3441. doi:10.1021/ol0510163

4. Hernandez-Rodriguez, M.; Juaristi, E. Tetrahedron 2007, 63, 7673. doi:10.1016/j.tet.2007.05.021 
5. Yang, D.; Li, X.; Fan, Y.-F.; Zhang, D.-W. J. Am. Chem. Soc. 2005, 127, 7996. doi:10.1021/ja051072z

6. Still, W. C. Acc. Chem. Res. 1996, 29, 155.

7. Sessler, J. L.; Andrievsky, A. Chem.-Eur. J. 1998, 4, 159. doi:10.1002/(SICI)1521-3765(199801)4:1<159::AID-CHEM159>3.0.CO ;2-N

8. Rebek, J., Jr.; Askew, B.; Nemeth, D.; Parris, K. J. Am. Chem. Soc. 1987, 109, 2432. doi:10.1021/ja00242a030

9. Galan, A.; Andreu, D.; Echavarren, A. M.; Prados, P.; de Mendoza, J. J. Am. Chem. Soc. 1992, 114, 1511. doi:10.1021/ja00030a074

10. Metzger, A.; Gloe, K.; Stephan, H.; Schmidtchen, F. P. J. Org. Chem. 1996, 61, 2051. doi:10.1021/jo951436d

11. Hong, J.-I.; Namgoong, S. K.; Barnardi, A.; Still, W. C. J. Am. Chem. Soc. 1991, 113, 5111. doi:10.1021/ja00013a084

12. Erickson, S. D.; Simon, J. A.; Still, W. C. J. Org. Chem. 1993, 58, 1305. doi:10.1021/jo00058a005

13. Yoon, S. S.; Still, W. C. J. Am. Chem. Soc. 1993, 115, 823. doi:10.1021/ja00055a083

14. DebRoy, P.; Banerjee, M.; Prasad, M.; Moulik, S. P.; Roy, S. Org. Lett. 2005, 7, 403. doi:10.1021/ol0476772

15. Clark, J. L.; Stezowski, J. J. J. Am. Chem. Soc. 2001, 123, 9880. doi:10.1021/ja003717v

16. Dobashi, A.; Hara, S. Tetrahedron Lett. 1983, 24, 1509. doi:10.1016/S0040-4039(00)81694-9

17. Schmuck, C.; Geiger, L. J. Am. Chem. Soc. 2005, 127, 10486. doi:10.1021/ja052699k

18. Schmuck, C. Chem. Commun. 1999, 843. doi:10.1039/a901126i

19. Davis, A. P.; Lawless, I. J. Chem. Commun. 1999, 9. doi:10.1039/a808245f

20. Vicent, C.; Fan, E.; Hamilton, A. D. Tetrahedron Lett. 1992, 33, 4269. doi:10.1016/S0040-4039(00)74235-3

21. Ghosh, K.; Saha, I.; Patra, A. Tetrahedron Lett. 2009, 50, 2392. doi:10.1016/j.tetlet.2009.02.215

22. Ghosh, K.; Masanta, G.; Chattopadhyay, A. P. Eur. J. Org. Chem. 2009, 4515. doi:10.1002/ejoc.200900471

23. Jeong, K.-S.; Cho, Y. L. Tetrahedron Lett. 1997, 38, 3279. doi:10.1016/S0040-4039(97)00602-3

24. Ghosh, K.; Sarkar, A. R.; Patra, A. Tetrahedron Lett. 2009, 50, 6557. doi:10.1016/j.tetlet.2009.09.043

25. Ghosh, K.; Sarkar, A. R.; Masanta, G. Tetrahedron Lett. 2007, 48, 8725. doi:10.1016/j.tetlet.2007.10.019

26. Ghosh, K.; Sarkar, A. R. Tetrahedron Lett. 2009, 50, 85. doi:10.1016/j.tetlet.2008.10.135

27. Wallance, K. J.; Belcher, W. J.; Turner, D. R.; Syed, K. F.; Steed, J. W. J. Am. Chem. Soc. 2003, 125, 9699. doi:10.1021/ja034921w

28. Bissel, R. A.; de Silva, A. P.; Gunaratne, H. Q. N.; Lynch, P. L. M.; Maguire, G. E. M.; Sandanayake, K. R. A. S. Chem. Soc. Rev. 1992, 21, 187. doi:10.1039/cs9922100187

29. Inoue, H.; Hida, M.; Nakashima, N.; Yoshihara, K. J. Phys. Chem. 1982, 86, 3184. doi:10.1021/j100213a024

30. Shiraishi, Y.; Kohno, Y.; Hirai, T. J. Phys. Chem. B 2005, 109, 19139. doi:10.1021/jp052645x

31. Job, P. Ann. Chim. Appl. 1928, 9, 113.

32. Turner, D. R.; Paterson, M. J.; Steed, J. W. J. Org. Chem. 2006, 71, 1598. doi:10.1021/jo052339f

33. Chou, P. T.; Wu, G. R.; Wei, C. Y.; Cheng, C. C.; Chang, C. P.; Hung, F. T. J. Phys. Chem. B 2000, 104, 7818. doi:10.1021/jp001001g

34. Gaussian 03, Revision C.01; Gaussian, Inc.: Wallingford CT, 2004.
35. GAMESS-US suite, April 11, 2008; NGS: UK, http://www.ngs.ac.uk/applications/chemistry/gamess. For a description see: "General Atomic and Molecular Electronic Structure System" M. W. Schmidt, K. K. Baldridge, J. A. Boatz, S. T. Elbert, M. S. Gordon, J. H. Jensen, S. Koseki, N. Matsunaga, K. A. Nguyen, S. Su, T. L. Windus, M. Dupuis, J. A. Montgomery J. Comput. Chem. 1993, 14, 1347-1363.

36. Podolyan, Y.; Leszczynski, J. Int. J. Quantum Chem. 2009, 109, 8. doi:10.1002/qua.21662

37. Krishnan, R.; Binkley, J. S.; Seeger, R.; Pople, J. A. J. Chem. Phys. 1980, 72, 650. doi:10.1063/1.438955

38. Becke, A. D. J. Chem. Phys. 1993, 98, 5648. doi:10.1063/1.464913

39. Stephens, P. J.; Devlin, F. J.; Chabalowski, C. F.; Frisch, M. J. J. Phys. Chem. 1994, 98, 11623. doi:10.1021/j100096a001

40. Chattaraj, P. K.; Sarkar, U.; Roy, D. R. Chem. Rev. 2006, 106, 2065. doi:10.1021/cr040109f

\section{License and Terms}

This is an Open Access article under the terms of the Creative Commons Attribution License

(http://creativecommons.org/licenses/by/2.0), which permits unrestricted use, distribution, and reproduction in any medium, provided the original work is properly cited.

The license is subject to the Beilstein Journal of Organic Chemistry terms and conditions:

(http://www.beilstein-journals.org/bjoc)

The definitive version of this article is the electronic one which can be found at: doi:10.3762/bjoc.6.139 